\title{
Pembelajaran Etnomatematika Untuk Menurunkan Kecemasan Matematika
}

\section{ETNOMATHEMATICS LEARNING TO REDUCE MATHEMATICAL ANXIETY}

\author{
Himmatul Ulya ${ }^{1}$, Ratri Rahayu ${ }^{2}$ \\ 1,2 Program Studi Pendidikan Matematika, Universitas Muria Kudus
}

* Korespondensi Penulis. e-mail: himmatul.ulya@umk.ac.id, Telp: +6285641521929

\begin{abstract}
Abstrak
Rendahnya kemampuan matematika peserta didik menyebabkan munculnya sikap ketidaksenangan terhadap matematika, dan sebaliknya. Ketidaksenangan tersebut akan memunculkan rasa takut dan cemas ketika belajar matematika. Kecemasan matematika juga dapat muncul karena proses pembelajaran matematika yang kurang menyenangkan. Tujuan penelitian ini yaitu: (1) mengetahui apakah rata-rata kecemasan matematika peserta didik yang diajar dengan pembelajaran probing-prompting bernuansa etnomatematika lebih rendah dari rata-rata kecemasan matematika peserta didik yang diajar dengan pembelajaran ekspositori dan (2) mengetahui penurunan kecemasan matematika peserta didik yang mengikuti pembelajaran probing-prompting bernuansa etnomatematika. Penelitian ini mengacu pada nonequivalent control group design yang merupakan bentuk desain dari kuasi eksperimen. Penelitian ini dilakukan di kelas IV SD NU Nawa Kartika Kudus pada semester genap tahun pelajaran 2016/2017. Teknik pengumpulan data yang digunakan yaitu dengan pemberian angket untuk mengukur kecemasan matematika peserta didik. Teknik analisis data dalam penelitian ini meliputi uji perbedaan rata-rata (uji t) dan uji gain untuk mengetahui penurunan kecemasan matematika peserta didik. Hasil penelitian menunjukkan bahwa rata-rata kecemasan matematika peserta didik yang diajar dengan pembelajaran probing-prompting bernuansa etnomatematika lebih rendah dari rata-rata kecemasan matematika peserta didik yang diajar dengan pembelajaran ekspositori dan kecemasan matematika peserta didik yang mengikuti pembelajaran probing-prompting bernuansa etnomatematika mengalami penurunan sebesar $48 \%$ dengan kategori sedang.
\end{abstract}

Kata Kunci: etnomatematika, kecemasan matematika, probing-prompting

\begin{abstract}
The students' low ability of mathematics leads to the emergence of displeasure attitude toward mathematics, and vice versa. Such displeasure will create fear and anxiety in learning mathematics. Mathematical anxiety can also arise because of the less enjoyable learning process of mathematics. The purpose of this study are: (1) to know whether the average of mathematical anxiety of students who are taught by probing-prompting learning based on ethnomatematics is lower than the average of mathematical anxiety of students who are taught by expository learning and (2) to know the decrease of mathematical anxiety of students who join probing-prompting learning based on etnomatematics. This study refers to nonequivalent control group design which is a design form of quasi experiment. This research was conducted in the $4^{\text {th }}$ grade of SD NU Nawa Kartika Kudus in the even semester of the academic year 2016/2017. Data collection techniques used were by giving questionnaires to measure students' mathematical anxiety. Data analysis techniques in this study include the average difference test ( $\mathrm{t}$ test) and gain test to determine the decrease of students' mathematical anxiety. The results showed that the average of mathematical anxiety of students who were taught by probing-prompting learning based on ethnomatematics was lower than the average of mathematical anxiety of students who were taught by expository learning and mathematical anxiety of students who joined the probingprompting learning based on ethnomatematika decreased by $48 \%$ with medium category.
\end{abstract}

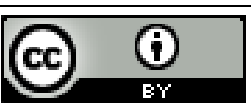

W : http://ejurnal.mercubuana-yogya.ac.id/index.php/mercumatika

E : mercumatika@mercubuana-yogya.ac.id

DOI: http://dx.doi.org/10.26486/jm.v2i2.295

Copyright (C) 2017 Universitas Mercu Buana Yogyakarta. All rights reserved. 
Keywords: ethnomathematics, mathematics anxiety, probing-prompting

\section{PENDAHULUAN}

Paradigma lama mengenai pembelajaran matematika yang berpusat pada guru hendaknya diperbaiki agar tujuan pembelajaran matematika dapat tercapai secara maksimal. Peserta didik tidak hanya mendengarkan guru dalam menjelaskan konsep, tetapi peserta didik harus ikut dalam proses menemukan konsep. Apabila pembelajaran matematika masih berlangsung seperti itu, maka akan berdampak pada rendahnya kemampuan matematis peserta didik. Kemampuan matematis peserta didik yang rendah akan berdampak pada minat peserta didik dalam belajar matematika. Setiana (2016) menyatakan bahwa dalam belajar matematika, peserta didik tidak hanya membutuhkan pengetahuan atau konsep tetapi juga perlu membangun minat dalam belajar matematika. Minat tersebut sebagai modal agar peserta didik tertarik dan tidak merasakan matematika menjadi momok untuk dirinya. Apabila peserta didik merasa tidak tertarik dan menganggap matematika sebagai beban, maka peserta didik akan menjadi cemas ketika belajar matematika.

Kecemasan matematika menurut Fiore (1999) yaitu kebingungan, ketidakmampuan, ketidakbertenagaan, dan keadaan kacau secara mental yang dialami orang ketika berhadapan dalam permasalahan dan pemecahan masalah matematika. Tobias menjelaskan bahwa kecemasan matematika merupakan ketegangan dan kecemasan yang dialami seseorang dalam memanipulasi bilangan atau angka serta pemecahan masalah yang berkaitan dengan matematika dalam kehidupan sehari-hari dan situasi akademik (Wahyudin, 2010). Jadi, kecemasan matematika yaitu perasaan takut dan cemas yang melanda seseorang ketika mengikuti kelas matematika, menyelesaikan masalah matematika, dan mendiskusikannya. Menurut Erdogan, et al. (2011), kecemasan matematika yang dialami peserta didik tergolong ke dalam state anxiety, karena kecemasan matematika tersebut muncul pada situasi tertentu, sebagai contoh ketika menghadapi pembelajaran atau ujian matematika.

Pembelajaran matematika yang tidak bervariasi menyebabkan pembelajaran tidak menyenangkan. Hal ini diketahui berdasarkan studi pendahuluan yang dilakukan di SD NU Nawa Kartika Kudus. Berdasarkan hasil wawancara dengan guru diperoleh keterangan bahwa guru dalam melakukan pembelajaran cenderung masih menggunakan model pembelajaran ekspositori yang kegiatan pembelajarannya didominasi oleh guru. Pembelajaran belum diarahkan agar peserta didik aktif dan berbasis keunggulan lokal. Selain itu, berdasarkan wawancara dan pemberian angket kepada peserta didik diperoleh informasi bahwa $70 \%$ peserta didik tidak menyukai pelajaran matematika, faktor penyebab peserta didik tidak tertarik dengan pelajaran matematika yaitu materi dan penyampaian guru (metode yang digunakan), rata-rata nilai matematika peserta didik tergolong cukup (kurang dari 70), dan peserta didik masih terbiasa belajar pasif karena selama pembelajaran berlangsung, guru lebih banyak menjelaskan materi menggunakan metode ceramah dan pemberian contoh-contoh, sedangkan peserta didik hanya mendengarkan dan menuliskan materi yang diajarkan oleh guru.

Berdasarkan hasil wawancara dari guru dan peserta didik tersebut disimpulkan bahwa pembelajaran matematika masih berorientasi pada guru. Pembelajaran seperti ini berdampak pada rendahnya ketertarikan peserta didik dalam belajar matematika. Ketertarikan peserta didik terhadap matematika yang rendah berdampak pada tingginya kecemasan matematika peserta didik. Kecemasan matematika peserta didik yang tinggi akan berdampak pada rendahnya 
kemampuan literasi matematika peserta didik. Hal ini diperoleh dari hasil pretes yang menunjukkan bahwa sebanyak 59\% peserta didik memiliki kecemasan matematika yang tinggi. Kecemasan matematika yang dialami peserta didik berakibat pada rendahnya kemampuan literasi matematika peserta didik. Hal ini berdasarkan data pretes yang menunjukkan hasil bahwa sebanyak $75 \%$ peserta didik memiliki kemampuan literasi matematika rendah.

Rendahnya kemampuan literasi matematika peserta didik juga didukung oleh data dari Trends in International Mathematics and Science Study (TIMSS) dan Programme for International Student Assessment (PISA) tahun 2015. Hasil TIMSS melaporkan bahwa Indonesia mendapat skor 397 (Mullis, et al., 2015) sedangkan hasil PISA Indonesia memperoleh peringkat 63 dari 69 negara (OECD, 2015). Hal ini berarti Indonesia berada di level bawah dan skor rata-rata peserta didik yang mengikuti terletak di bawah skor rata-rata internasional. Hasil tersebut berarti bahwa pembelajaran matematika di Indonesia belum memaksimalkan kemampuan literasi matematika.

Kecemasan matematika akan berdampak negatif pada pengetahuan matematika dan kemampuan matematis peserta didik (Ashcraft dan Krause, 2007; Suinn, Taylor, dan Edwards, 1988). Hal ini diperkuat Anita (2014) yang menyatakan bahwa kecemasan matematika dengan kemampuan matematis peserta didik memiliki hubungan yang negatif. Hal ini berarti bahwa jika peserta didik mengalami kecemasan matematika yang tinggi, maka kemampuan matematika peserta didik tersebut rendah. Tingkat kecemasan peserta didik sangat berpengaruh terhadap prestasi belajarnya. Apabila peserta didik mampu mengendalikan kecemasannya maka peserta didik tersebut akan mampu mengoptimalkan kemampuannya dalam belajar matematika.

Penelitian Indiyani dan Listiara (2006) telah dilakukan untuk meminimalisir kecemasan matematika. Penelitian ini menggunakan metode cooperative learning agar peserta didik tidak cemas terhadap matematika. Hasilnya yaitu ada perbedaan signifikan kecemasan matematika peserta didik pada kelas eksperimen dan kontrol. Kecemasan dalam pembelajaran matematika peserta didik kelas eksperimen mengalami penurunan, sedangkan pada kelas kontrol tidak terjadi penurunan kecemasan matematika.

Berdasarkan uraian di atas, kecemasan matematika yang dialami peserta didik hendaknya dapat diminimalisir melalui perbaikan proses pembelajaran matematika. Alur pembelajaran matematika perlu dialihkan dengan membiasakan peserta didik belajar aktif, kreatif, dan menyenangkan sehingga diharapkan kecemasan matematika dapat diturunkan dan berakibat pada kemampuan literasi matematika yang meningkat. Alternatif pembelajaran yang dapat dipakai untuk menyelesaikan masalah tersebut yaitu pembelajaran inovatif dengan menerapkan pembelajaran bernuansa etnomatematika yang dikemas dalam pembelajaran probing-prompting.

Pada pembelajaran probing-prompting, guru menyajikan pertanyaan-pertanyaan yang menuntun peserta didik mengaitkan pengetahuan dan pengalamannya sehingga peserta didik dapat mengonstruksi konsep, prinsip, dan aturan menjadi pengetahuan baru (Suyatno:2009; Ulya:2012). Melalui pembelajaran tersebut peserta didik terbiasa untuk berinteraksi dan mendapatkan pertanyaan yang membantunya untuk menemukan konsep matematika yang baru (Ulya dan Rahayu, 2017). Pembelajaran probingprompting bernuansa etnomatematika yaitu pembelajaran yang mengangkat keunggulan 
budaya daerah Kudus sebagai referensi dalam mengajarkan materi pecahan yang dikemas dalam pembelajaran probing-prompting. Hal tersebut sejalan dengan Wahyuni, Tias, dan Sani (2013) yang menyatakan bahwa apabila etnomatematika diterapkan sebagai pendekatan dalam pembelajaran, maka konsep matematika yang dipelajari akan berhubungan dengan budaya peserta didik. Hal ini akan memudahkan peserta didik dalam memahami konsep tersebut karena berkaitan langsung dengan budayanya. Hal ini bertujuan untuk menciptakan pembelajaran yang menyenangkan sehingga diharapkan dapat menurunkan kecemasan matematika peserta didik.

Berdasarkan latar belakang yang telah diuraikan, maka permasalahan dalam penelitian ini, yaitu (1) apakah rata-rata kecemasan matematika peserta didik yang diajar dengan pembelajaran probing-prompting bernuansa etnomatematika lebih rendah dari rata-rata kecemasan matematika peserta didik yang diajar dengan pembelajaran ekspositori dan (2) bagaimana penurunan kecemasan matematika peserta didik yang mengikuti pembelajaran probing-prompting bernuansa etnomatematika. Tujuan dalam penelitian ini yaitu: (1) mengetahui apakah rata-rata kecemasan matematika peserta didik yang diajar dengan pembelajaran probing-prompting bernuansa etnomatematika lebih rendah dari rata-rata kecemasan matematika peserta didik yang diajar dengan pembelajaran ekspositori dan (2) mengetahui penurunan kecemasan matematika peserta didik yang mengikuti pembelajaran probing-prompting bernuansa etnomatematika.

\section{METODE}

Berisi jenis penelitian, waktu dan tempat penelitian, target/sasaran, subjek penelitian, Penelitian ini menggunakan nonequivalent control group design yang merupakan bentuk desain dari kuasi eksperimen. Penelitian ini dilakukan di kelas IV SD NU Nawa Kartika Kudus pada semester genap tahun pelajaran 2016/2017. Pemilihan kelompok sampel melalui teknik random sampling dengan memperhatikan ciri-ciri relatif pada kelas IV, yaitu pembelajaran yang dilakukan menggunakan kurikulum yang sama dan penempatan kelas bukan dilihat dari rangking (tidak ada kelas unggulan) sehingga peserta didik menempati kelas secara acak. Di dalam penelitian ini dipilih dua kelas secara acak yaitu kelas IV C sebagai kelas eksperimen sedangkan kelas IV D sebagai kelas kontrol. Desain dalam penelitian ini ditunjukkan pada Tabel 1 berikut.

Tabel 1. Desain Penelitian

\begin{tabular}{cccc}
\hline Kelompok & Pretest & Perlakuan & Posttest \\
\hline Eksperimen & $T_{1}$ & $\mathrm{E}$ & $T_{2}$ \\
Kontrol & $T_{1}$ & $\mathrm{~K}$ & $T_{2}$ \\
\hline
\end{tabular}

(Sugiyono, 2010)

Keterangan:

$T_{1}:$ Tes sebelum pembelajaran (pretest) 
$T_{2}:$ Tes setelah pembelajaran (posttest)

E : Implementasi pembelajaran probing-prompting bernuansa etnomatematika

$\mathrm{K}$ : Implementasi pembelajaran ekspositori

Sumber data dalam penelitian ini diperoleh melalui wawancara pada studi pendahuluan dan lembar angket untuk mengukur kecemasan matematika. Teknik pengumpulan data yang digunakan yakni menggunakan angket untuk mengukur kecemasan matematika peserta didik sebelum dan setelah pembelajaran. Teknik analisis data yang digunakan meliputi uji perbedaan rata-rata (uji t) dan uji gain untuk mengetahui penurunan kecemasan matematika peserta didik.

\section{HASIL DAN PEMBAHASAN}

Sebelum dilakukan pengujian hipotesis untuk uji perbedaan rata-rata dan uji gain, maka perlu dilakukan uji pendahuluan. Uji prasyarat yang digunakan meliputi normalitas dan homogenitas. Uji normalitas dalam penelitian ini menggunakan Kolmogorov-Smirnov, sedangkan uji homogenitas menggunakan Levene. Berdasarkan uji prasyarat tersebut, disimpulkan bahwa kelompok eksperimen dan kontrol berasal dari populasi yang memiliki distribusi normal dan homogen (variansnya sama).

\section{Uji Perbedaan Rata-Rata}

Uji perbedaan rata-rata dipakai untuk membandingkan rerata kecemasan matematika peserta didik pada kelas eksperimen dan kelas kontrol. Uji ini melalui uji t (independent sample t-test) berbantuan SPSS. Hipotesis untuk uji ini yaitu $H_{0}: \mu_{1}=\mu_{2}$,

artinya tidak ada perbedaan rata-rata kecemasan matematika peserta didik antara kedua kelompok sampel, sedangkan $H_{1}: \mu_{1} \neq \mu_{2}$, artinya ada perbedaan rata-rata kecemasan matematika peserta didik antara kedua kelompok sampel. Kriteria pengujian hipotesis ini yaitu $H_{0}$ ditolak apabila nilai Sig. (2-tailed) $<0,05$. Hasil pengolahan data diperoleh

bahwa Sig. (2-tailed) bernilai 0,000 yang artinya nilai signifikansi tersebut kurang dari 0,05 . Hal ini disimpulkan bahwa $H_{0}$ ditolak, yang artinya ada perbedaan rata-rata

kecemasan matematika peserta didik antara kedua kelompok sampel. Berdasarkan hal itu ditafsirkan bahwa rata-rata kecemasan matematika peserta didik yang belajar dengan pembelajaran probing-prompting bernuansa etnomatematika lebih rendah jika dibandingkan dengan rata-rata kecemasan matematika peserta didik yang menerima pembelajaran ekspositori. 


\section{Uji Gain}

Uji gain digunakan untuk menganalisis penurunan kecemasan matematika peserta didik sebelum dan setelah belajar melalui pembelajaran etnomatematika yang dikemas dalam pembelajaran probing-prompting. Perhitungan uji gain dilakukan dengan menghitung selisih antara nilai awal (sebelum pembelajaran) dan nilai akhir (sesudah pembelajaran), kemudian dibagi dengan selisih antara nilai maksimum dan nilai awal (sebelum pembelajaran). Rekapitulasi penurunan kecemasan matematika individual dengan menggunakan uji gain ditunjukkan pada Tabel 2 dan yang secara klasikal disajikan pada Tabel 3 .

Tabel 2. Penurunan Kecemasan Matematika Secara Individual

\begin{tabular}{ccc}
\hline Kriteria & $\begin{array}{c}\text { Banyaknya } \\
\text { Peserta } \\
\text { Didik }\end{array}$ & Persentase \\
\hline Rendah & 10 & $22,73 \%$ \\
Sedang & 25 & $56,82 \%$ \\
Tinggi & 9 & $20,45 \%$ \\
\hline
\end{tabular}

Tabel 2 menunjukkan bahwa paling banyak penurunan kecemasan matematika peserta didik terjadi pada level sedang yakni sebesar 56,82\% (25 peserta didik), sebanyak 10 peserta didik mengalami penurunan kecemasan matematika pada tingkat rendah dan kecemasan matematika menurun pada level tinggi sebanyak 9 peserta didik.

Tabel 3. Penurunan Kecemasan Matematika Secara Klasikal

\begin{tabular}{ccc}
\hline $\begin{array}{c}\text { Rata-Rata } \\
\text { Pretest }\end{array}$ & $\begin{array}{c}\text { Rata-Rata } \\
\text { Posttest }\end{array}$ & $\langle g\rangle$ \\
\hline 84,30 & 97,00 & 0,48 \\
\hline
\end{tabular}

Pada Tabel 3 dapat ditafsirkan bahwa secara klasikal peserta didik mengalami penurunan kecemasan matematika mencapai 0,48 atau $48 \%$. Hal ini berarti bahwa ratarata penurunan kecemasan matematika peserta didik secara klasikal masuk dalam kategori sedang.

Rata-rata kecemasan matematika peserta didik yang diberi perlakuan pembelajaran probing-prompting bernuansa etnomatematika lebih rendah jika dibandingkan dengan rata-rata kecemasan matematika peserta didik yang belajar dengan pembelajaran ekspositori. Kecemasan matematika peserta didik kelas eksperimen lebih rendah karena peserta didik tertarik dalam pembelajaran matematika yang dikaitkan dengan budaya daerah Kudus. Peserta lebih mudah memahami materi dan merasa tidak asing dengan apa yang dipelajari. Hal ini diperkuat oleh Ulya (2016), yaitu pembelajaran etnomatematika membantu peserta didik lebih mudah dalam mempelajari 
konsep karena berhubungan langsung dengan praktik budaya lokal. Oleh karena konsep matematika dapat dipahami lebih mudah, maka peserta didik lebih berminat dan termotivasi dalam menyelesaikan masalah sehingga kecemasan matematika menjadi berkurang.

Dalam mempelajari matematika yang dikaitkan dengan budaya, ada pula peserta didik yang baru mengetahui mengenai keunggulan-keunggulan lokal Kudus khususnya yang berasal dari daerah selain Kudus. Meskipun baru mengenal keunggulan lokal Kudus, peserta didik tersebut menjadi tertarik dan bersemangat mempelajari matematika. Hal ini sama dengan pendapat Arisetyawan, et al. (2014) yang berpendapat bahwa budaya yang dimasukkan dalam pembelajaran matematika akan menciptakan pembelajaran menjadi bermakna dan dapat meningkatkan ranah kognitif peserta didik.

Kecemasan matematika peserta didik menurun setelah diberi perlakuan pembelajaran probing-prompting bernuansa etnomatematika. Anita (2014) menyatakan bahwa kondisi pembelajaran di kelas yang kurang menyenangkan dapat menyebabkan kecemasan matematika menjadi lebih parah. Namun melalui pembelajaran probingprompting bernuansa etnomatematika, peserta didik belajar secara menyanangkan. Di dalam pembelajaran tersebut peserta didik aktif berdiskusi dengan panduan Lembar Kerja Sisiwa (LKS), saling bertukar pikiran dengan teman kelompoknya, sehingga suasana kelas menjadi lebih dinamis. Peserta didik terbiasa berinteraksi dengan peserta didik lain atau dengan guru sehingga peserta didik tidak lagi menjadi takut dan cemas ketika belajar matematika.

\section{KESIMPULAN}

Berdasarkan hasil penelitian disimpulkan bahwa (1) rata-rata kecemasan matematika peserta didik yang diajar dengan pembelajaran probing-prompting bernuansa etnomatematika lebih rendah dari rata-rata kecemasan matematika peserta didik yang diajar dengan pembelajaran ekspositori, dan (2) kecemasan matematika peserta didik yang mengikuti pembelajaran probing-prompting bernuansa etnomatematika mengalami penurunan sebesar $48 \%$ dengan kategori sedang.

\section{DAFTAR PUSTAKA}

Anita, I. W. (2014). Pengaruh Kecemasan Matematika (Mathematics Anxiety) Terhadap Kemampuan Koneksi Matematis Siswa SMP. Jurnal Ilmiah Program Studi Matematika STKIP Siliwangi Bandung, 3(1): 125-132.

Arisetyawan, A., et al. (2014). Study of Ethnomathematics: A Lesson from the Baduy Culture. International Journal of Education and Research, 2(10): 681-688.

Ashcraft, M. H., dan Krause, J. A. (2007). Working Memory, Math Performance, and Math Anxiety. Psychonomic Bulletin \& Review, 14(2): 243-248. 
Erdogan, A. et al. (2011). Prediction of High School Students' Mathematics Anxiety by Their Achievement Motivation and Social Comparison. Elementary Education Online, 10(2): 646-652.

Fiore, G. (1999). Math-Abused Students: Are We Prepared To Teach Them? Mathematics Teacher, 92(5), 403-406.

Indiyani, N.E. dan Listiara, A. (2006). Efektivitas Metode Pembelajaran Gotong Royong (Cooperative Learning) untuk Menurunkan Kecemasan Siswa dalam Menghadapi Pelajaran Matematika (Suatu Studi Eksperimental Pada Siswa Di SMP 26 Semarang). Jurnal Psikologi Universitas Diponegoro, 3(1): 10-28.

Mullis, I.V.S., et al. (2015). TIMSS 2015 International Results in Mathematics. Chestnut Hill, MA: TIMSS \& PIRLS International Study Center, Boston College.

Organization for Economic Coperation and Development (OECD). (2015). PISA 2015 Results in Focus. Tersedia di https://www.oecd.org/pisa/pisa-2015-results-in-focus.pdf.

Setiana, D.S. (2016). Komparasi Penerapan Metode Pembelajaran CTL dan Open-Ended dengan Memperhatikan Gaya Belajar Ditinjau dari Prestasi dan Minat Belajar Matematika. Jurnal Mercumatika, 1(1): 13-32.

Sugiyono. (2010). Metode Penelitian Pendidikan (Pendekatan Kuatitatif, Kualitatif dan R\&D). Bandung: Alfabeta.

Suinn, R. M., Taylor, S., dan Edwards, R. W. (1988). Suinn Mathematics Anxiety Rating Scale for Elementary School Students (MARS-E): Psychometric and Normative Data. Educational and Psychological Measurement, 48(4): 979-986.

Suyatno. (2009). Menjelajah Pembelajaran Inovatif. Sidoarjo: Masmedia Buana Pustaka.

Ulya, H., Masrukan, dan Kartono. (2012). Keefektifan Penerapan Model Pembelajaran Kooperatif Tipe Probing-Prompting dengan Penilaian Produk. Unnes Journal of Mathematics Education, 1(1): 26-31.

Ulya, H. (2016). Pembelajaran Matematika Berbasis Etnomatematika untuk Membangun Karakter Cinta Tanah Air dan Kreativitas Belajar Matematika. Prosiding Seminar Nasional Psikologi Universitas Muria Kudus: 29-39.

Ulya, H. dan Rahayu, R. (2017). Uji Kelayakan Perangkat Pembelajaran Probing-Prompting Berbasis Keunggulan Lokal Kudus. Prosiding Seminar Nasional Hari Pendidikan Nasional FKIP Universitas Kristen Satya Wacana, 379-388.

Wahyudin. (2010). Monograf: Kecemasan Matematika. Bandung: Program Studi Pendidikan Matematika SPS UPI.

Wahyuni, A., Tias, A.A.W., dan Sani, B. (2013). Peran Etnomatematika dalam Membangun Karakter Bangsa. Prosiding Seminar Nasional Pendidikan Matematika Universitas Negeri Yogyakarta, 113-114. 